\title{
Estimation of atmospheric transmissivity of solar radiation from precipitation in the Himalaya and the Tibetan Plateau
}

\author{
Yoshihiro MATSUDA, Koji FUJITA, Yutaka AGETA, Akiko SAKAI \\ Graduate School of Environmental Studies, Nagoya University, Nagoya 464-8601, Japan \\ E-mail: matsuda_snowman@nagoya-u.jp
}

\begin{abstract}
Though solar radiation is important for glacier mass-balance simulation, solar radiation data are not always available. As a result of analyzing meteorological data measured in the Himalaya and the Tibetan Plateau, a favorable correlation between precipitation and atmospheric transmissivity of solar radiation is found in terms of monthly values. Monthly mean solar radiation is derived from the relationship between atmospheric transmissivity of solar radiation and precipitation with input of monthly precipitation, latitude, skyline and time. The differences between estimated and observed monthly mean solar radiation are $<40 \mathrm{~W} \mathrm{~m}^{-2}$ in most cases. However, the differences at some sites are significantly large. The error in the estimated solar radiation during the monsoon season can be large when the monthly mean precipitation rate is about $5 \mathrm{~mm} \mathrm{~d}^{-1}$. Though the error in the estimated solar radiation during the non-monsoon season is generally small due to low precipitation in the Himalaya and the Tibetan Plateau during this season, it can exceed $100 \mathrm{~W} \mathrm{~m}^{-2}$.
\end{abstract}

\section{INTRODUCTION}

Studies on glacier mass balance are regarded as important in connection with sea-level rise, water resources and other concerns related to climatic change (e.g. Dyurgerov and Meier, 1997; Liu and others, 1999; Houghton and others, 2001). Mass-balance models are necessary to examine the response of glaciers to climate change and to understand spatial and temporal variations in mass balance. However, only a few numerical studies of mass balance based on physical energy-balance simulations at the glacier surface have been performed in the Himalaya and the Tibetan Plateau (e.g. Kayastha and others, 1999; Fujita and Ageta, 2000) due to the lack of high-quality meteorological data in these regions.

Temperature-index models are widely used for estimating mass balance when available data are limited. The most commonly used temperature-index model is the degree-day model, which predicts ablation as the product of the sum of all positive daily mean air temperatures in ${ }^{\circ} \mathrm{C}$ and the degree-day factor. The simplicity of the degree-day method has advantages. However, degree-day factors vary spatially and temporally (Braithwaite and Zhang, 2000; Kayastha and others, 2000, 2003; Hock, 2003) because they are affected by the complex process of surface energy balance contributed by temperature, solar radiation and other environmental conditions. Therefore, the degree-day factor must be essentially determined by means of field data of ablation and air temperature.

Since absorbed solar radiation is generally the dominant component of the surface energy balance over melting glaciers (e.g. Ohata and Higuchi, 1980; Bamber and Payne, 2004; Sicart and others, 2005), not only air temperature but also solar radiation must be a key factor even in the simplest mass-balance model (Oerlemans, 2001). Therefore, not only physically based energy-balance models but also simple mass-balance models use solar radiation as input (e.g. Martinec, 1989; Hock, 1999; Oerlemans, 2001). Strong solar radiation in low-latitude regions also enhances its importance for estimating mass balance in the Himalaya and the Tibetan Plateau.
Re-analysis products, such as by the US National Centers for Environmental Prediction/National Center for Atmospheric Research (NCEP/NCAR; Kalnay and others, 1996) and by the European Centre for Medium-Range Weather Forecasts (ECMWF; Simmons and Gibson, 2000), would be useful for estimating solar radiation and other meteorological variables needed as input for mass-balance models (e.g. Reichert and others, 2001). Downscaling re-analysis data, however, is an inevitable step for small glaciers and ice caps due to the spatial resolution of re-analyses (e.g. $2.5^{\circ} \times 2.5^{\circ}$ of NCEP/NCAR Re-analysis and ERA-40 by ECMWF). Moreover, data from several or more decades ago (e.g. before 1948 for NCEP/NCAR Re-analysis) are not available.

Atmospheric models such as general circulation models (GCMs) can simulate solar radiation and other climatic conditions and enable simulation of the response of the glacier mass balance to climate change (e.g. Glover, 1999; Wild and Ohmura, 2000; Reichert and others, 2001; Casal and others, 2004). However, the computing costs of atmospheric models limit spatial resolution.

Since data on solar radiation are often unavailable, some previous studies derived solar radiation from other parameters. The dependence of solar radiation on cloud amount has often been examined (e.g. Dobson and Smith, 1989; Oerlemans, 1993; Bintanja and Van den Broeke, 1996; Greuell and others, 1997). Walter and others (2005) used the daily air-temperature range for estimating solar radiation. Though there are many meteorological stations in the Himalaya and the Tibetan Plateau (e.g. Chalise and others, 1996; Liu and Chen, 2000), the distribution density of meteorological stations is not uniform, and data on the cloud amount and daily air-temperature range are difficult to obtain in some areas. Moreover, meteorological station recordings do not provide information about pre-instrumental periods.

Analyses of ice cores and tree rings help to reveal past climatic information. Many analyses of ice cores (e.g. Yao and Thompson, 1992; Duan and Yao, 2003; Thompson and others, 2003) or tree rings (e.g. Zhang and others, 2003; Feng and $\mathrm{Hu}, 2005$; Singh and Yadav, 2005) have focused on temperature and/or precipitation in the Himalaya and the 


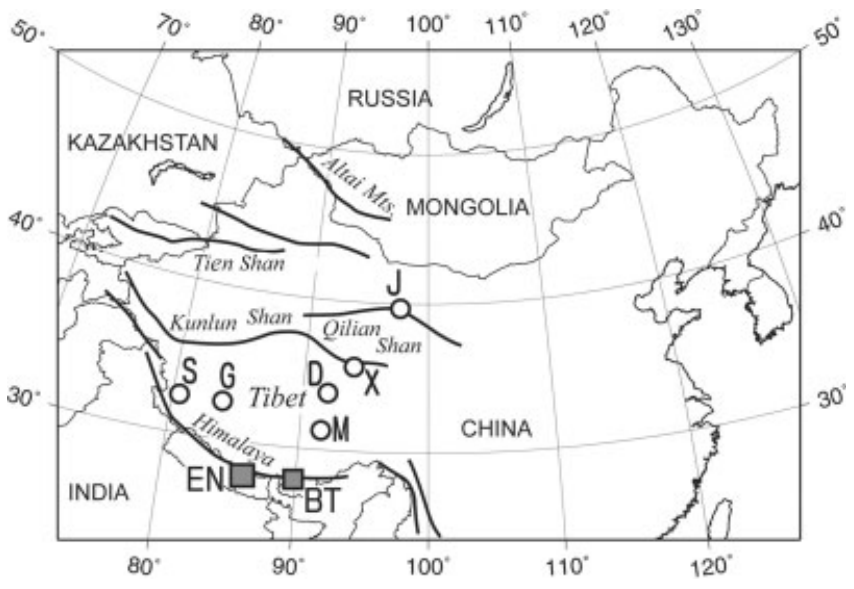

Fig. 1. Location map of study area. $D, G, J, M, S$ and $X$ denote D105, ${ }^{1,2}$ Gaize, ${ }^{3}$ July 1 st glacier, ${ }^{4}$ MS3608, ${ }^{3}$ Shiquanhe, ${ }^{3,5,6}$ and D66, ${ }^{3}$ respectively. EN denotes the area including AX010 glacier, ${ }^{7}$ Yala glacier $^{8}$ and Lirung glacier. ${ }^{8}$ BT denotes the area including Ganju La glacier ${ }^{9}$ and Lugge glacier. ${ }^{9}$ References are as follows: ${ }^{1}$ Ohta and Ageta (1996); ${ }^{2}$ Ueno and Ohata (1996); ${ }^{3}$ GAME-Tibet (http://monsoon.t.u-tokyo.ac.jp/tibet/); ${ }^{4}$ Matsuda and others (2004); ${ }^{5}$ Shiobara and Asano (1992); ${ }^{6} \mathrm{Xu}$ and Haginoya (2001); ${ }^{7}$ Ageta and others (1980); ${ }^{8}$ Fujita and others (1997); ${ }^{9}$ Ageta and Kohshima (2004).

Tibetan Plateau. Indeed, Wang and others (2001) reconstructed past temperature in China from ice-core and treering data, and past accumulation rates estimated from nonmelting ice cores can reveal past precipitation amounts. Other meteorological variables, however, are difficult to quantify reliably by analyses of ice cores or tree rings. If there were a method of estimating solar radiation from precipitation, it would be a useful tool at times when solar radiation cannot be obtained by other methods. Therefore we propose a new approach for deriving the solar radiation from precipitation.

\section{APPROACH}

Solar radiation on the terrestrial surface, $S\left(\mathrm{~W} \mathrm{~m}^{-2}\right)$, can be expressed as:

$$
S=\tau T S_{0}
$$

where $\tau$ is atmospheric transmissivity of solar radiation, $T$ is topographic effects on transmissivity of solar radiation, and $S_{0}$ is solar radiation at the top of the atmosphere $\left(\mathrm{W} \mathrm{m}^{-2}\right)$. Since $S_{0}$ can be calculated when the latitude of the location and time are given, solar radiation can be estimated if $\tau$ and $T$ are obtained.

The variable $\tau$ depends on atmospheric conditions such as cloud amount, cloud optical thickness, absorption by water vapor and other gases, and aerosol extinction. The term causing the largest uncertainty in the estimate of solar radiation is the cloud factor (Bamber and Payne, 2004). As precipitation is closely linked to clouds and is necessary for mass-balance calculations anyway, an examination of the relation between $\tau$ and precipitation can be meaningful, though it is obvious that precipitation amounts cannot represent instantaneous atmospheric conditions.

The variable $T$ depends on many factors such as shading and reflections from surrounding slopes, and shading by surrounding mountains is generally the most important factor for the variation of $S$. The variable $S$ can be split into a
Table 1. Measurement periods of precipitation and solar radiation. The monsoon season and the non-monsoon season run from May to September and from October to April, respectively

$\begin{array}{lll}\text { Measurement site } & \begin{array}{l}\text { Measurement } \\ \text { period }\end{array} & \text { Number of months } \\ & \text { Monsoon Non-monsoon }\end{array}$

\begin{tabular}{llcc}
\hline D105 & Jun.-Jul. 1993 & 2 & - \\
D66 & Jun.-Aug. 1998 & 3 & - \\
Gaize & May-Sept. 1998 & 5 & - \\
MS3608 & Jun.-Jul. 1998 & 2 & - \\
Shiquanhe & May-Aug. 1998 & 4 & - \\
AX010 glacier & Jun.-Sept. 1978 & 4 & - \\
Ganju La glacier & Oct. 2003-Aug. 2004 & 4 & 7 \\
July 1st glacier & Jul. 2002-Aug. 2005 & 17 & 21 \\
Lirung glacier & Jun.-Sept. 1996 & 4 & - \\
Lugge glacier & Oct. 2002-Sept. 2004 & 10 & 14 \\
Yala glacier & Jun.-Jul. 1996 & 2 & - \\
Total & & 57 & 42 \\
& & & \\
\hline
\end{tabular}

direct part and a diffusive part. The magnitude of shading in the direct part and the diffusive part is different, and the ratio of the direct part to the diffusive part depends on the atmospheric conditions. Therefore, we calculated the average values of $T S_{0}$ with the assumption that $T=0$ when the sun elevation is below the skyline of the surrounding mountains and $T=1$ otherwise.

\section{DATA AND MEASUREMENT SITES}

We analyzed the dataset of precipitation and $S$ measured at 11 sites in the Himalaya and the Tibetan Plateau. The locations of the measurement sites are shown in Figure 1, and the measured monthly precipitation, monthly means of observed $S$ and monthly mean air temperature used in this study are shown in Figure 2. The altitudes of these measurement sites range from 4279 to $5350 \mathrm{~m}$. Precipitation during the monsoon season (May-September) is dominant, while during the non-monsoon season (October-April) little precipitation occurs in the Himalaya and the Tibetan Plateau (e.g. Ding and Kang, 1985; Dai, 1990; Chen and others, 2004). The fact that little surface-level increase is measured during the non-monsoon season at Xiao Dongkemadi glacier, which is near D105, (Seko and others, 1994) and at July 1st (Qiyi) glacier (Matsuda and others, unpublished information) confirms that there is little precipitation during this period even in the mountain regions. The annual precipitation varies widely, from a few hundred $\mathrm{mm}$ on the northwestern Tibetan Plateau to $>2000 \mathrm{~mm}$ on the south side of the Himalaya. The measurement periods of meteorological data used in this study are summarized in Table 1.

Meteorological data are point measurement values and do not reflect the mean distributed meteorological conditions. All meteorological measurements were taken at the same location, except for Yala glacier. Precipitation at Yala glacier was measured outside of the glacier (5110 ma.s.l.), while the other meteorological variables were measured on the glacier (5350 ma.s.l.), with a horizontal distance between two points of about $1 \mathrm{~km}$. The measurement site at Lirung glacier was a debris-covered area on the glacier, while measurements at AX010, Ganju La and July 1st glaciers were made outside and near the terminus of the 


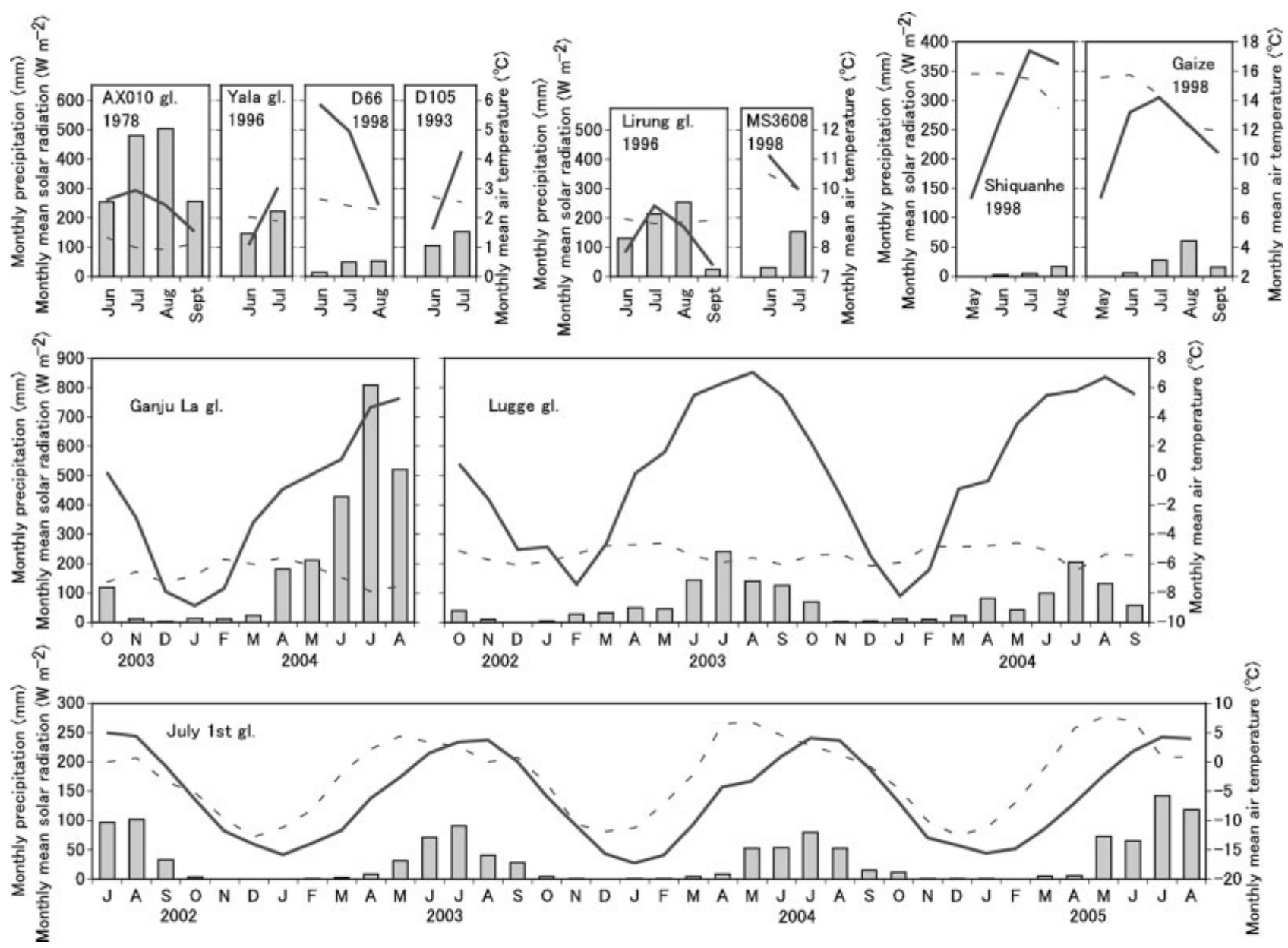

Fig. 2. Measured monthly precipitation (bar), monthly mean solar radiation (dashed line) and monthly mean air temperature (solid line) at 11 measurement sites in Figure 1. Precipitation at D105 was adjusted to the value of the bush gauge.

glaciers. The measurement site at Lugge glacier was a debriscovered area on the terminal dead ice. D105, D66, MS3608, Gaize and Shiquanhe stations were in open, flat fields. All measurement sites except those at Ganju La and Lugge glaciers were visited several times during the measurement period. Instruments at July 1st glacier were checked every few days during the summers of 2002-05, but were not checked during other seasons. Instruments at Ganju La and Lugge glaciers were checked once a year (autumn) due to the difficulties of reaching and staying at measurement sites.

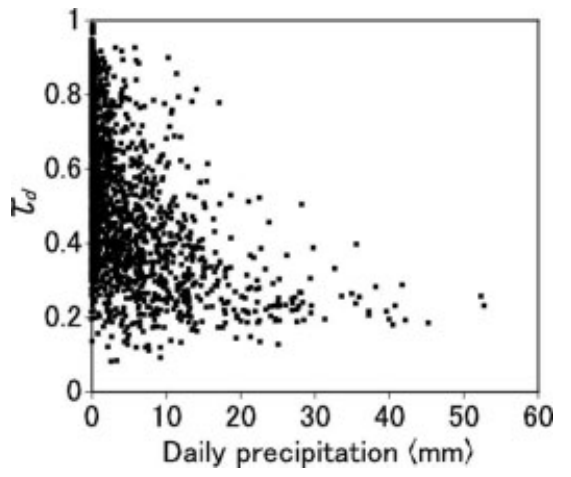

Fig. 3. Daily atmospheric transmissivity of solar radiation, $\tau_{\mathrm{d}}$, and daily precipitation, $p_{\mathrm{d}}$.
Precipitation data were obtained manually at AX010 glacier by regularly measuring the accumulated precipitation in a tank, and automatically at other sites. Weighing rain gauges were used at D66 and MS3608. Unheated tipping-bucket rain gauges were used at the other sites, i.e. D105, Gaize, Shiquanhe, and Ganju La, July 1st, Lirung, Lugge and Yala glaciers. Tipping-bucket rain gauges cannot accurately measure precipitation falling as snow or when the bucket is frozen; and as reported previously, measurements of precipitation, particularly solid precipitation, are adversely affected by strong winds. Therefore, measured

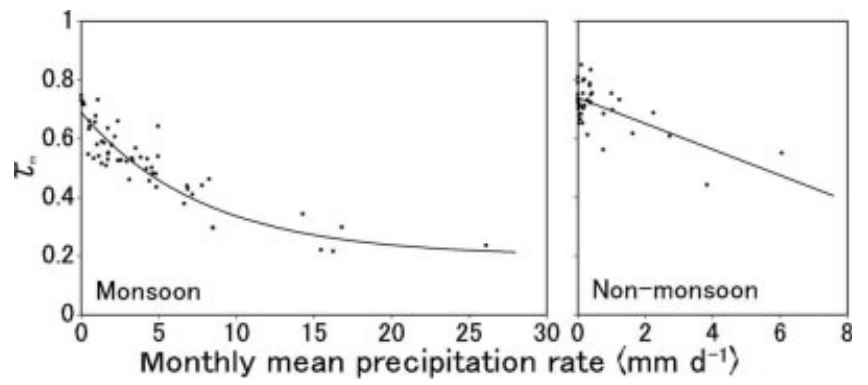

Fig. 4. Monthly atmospheric transmissivity of solar radiation, $\tau_{\mathrm{m}}$, and monthly mean precipitation rate, $p_{\mathrm{m}}$, in the monsoon season (May-September) and the non-monsoon season (October-April). Solid lines denote the approximate lines expressed by Equation (2). 


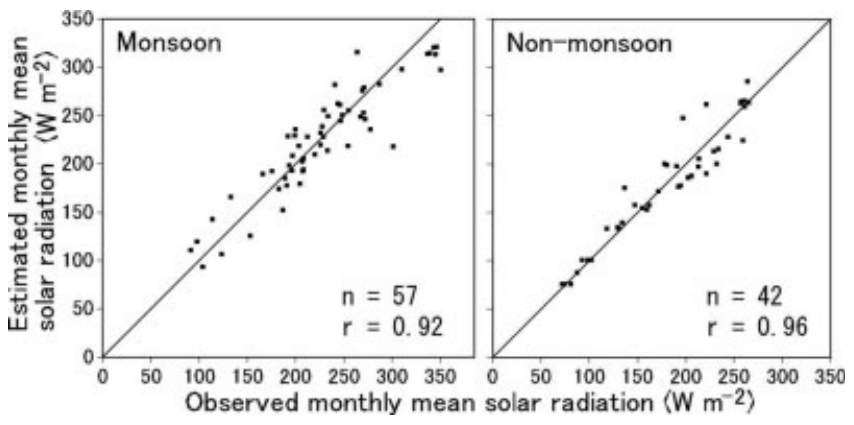

Fig. 5. Estimated and observed monthly mean solar radiation at 11 measurement sites. Solid line denotes $1: 1$ relationship. The $n$ and $r$ denote the number of data and correlation coefficient, respectively.

precipitation should be adjusted to the 'true' value of the bush gauge or Double Fence Intercomparison Reference (DFIR), which is a practical secondary standard (e.g. Goodison and others, 1998). Precipitation at D105 was adjusted to the value of the bush gauge (Ueno and Ohata, 1996). Since the catch ratios of gauges, which are the ratios of measured precipitation to DFIR value, at the other ten measurement sites are unknown, precipitation measured at these sites was not corrected. The potential impact of the measurement error on this study is discussed later.

The variable $S$ was measured by pyranometers installed horizontally at all sites. The pyranometers used were EKO MS-800, EKO MS-801, EKO-MS601, Aanderaa solar radiation sensor 2770 and the Robitzsch pyranometer (manufacturer unknown). The Robitzsch pyranometer was used at AX010 glacier only, and $S$ at AX010 glacier was corrected by comparison with that simultaneously measured by the EKO MS-42 pyranometer. All solar radiation data were expected to be accurate to within $\pm 5 \%$.

The skylines of surrounding mountains were used for calculating daily and monthly means of $T S_{0}$. The direction and elevation angle of skylines were surveyed at AX010, Ganju La, July 1st, Lirung and Yala glaciers by means of a transit compass. Digital elevation model (DEM) data of ASTER (Advanced Spaceborne Thermal Emission and Reflection Radiometer) Level 3A01 product (http:// www.science.aster.ersdac.or.jp/en/index.html) with $15 \mathrm{~m}$ spatial resolution were used for obtaining the skyline at Lugge glacier, and 3 arcsec DEM data by the Shuttle Radar Topography Mission (SRTM) (http://srtm.usgs.gov/, http:// www2.jpl.nasa.gov/srtm/index.html) were used at D105, D66, Gaize, MS3608 and Shiquanhe.

\section{RESULTS AND DISCUSSION}

\section{Estimating atmospheric transmissivity of solar radiation}

We calculated daily atmospheric transmissivity of solar radiation, $\tau_{\mathrm{d}}$, which is defined as the ratio of daily mean observed $S$ to daily mean of $T S_{0}$. The $\tau_{\mathrm{d}}$ and daily precipitation, $p_{\mathrm{d}}(\mathrm{mm})$, are shown in Figure 3 . The $\tau_{\mathrm{d}}$ converges toward about 0.2 with the increase of $p_{\mathrm{d}}$. The range of $\tau_{\mathrm{d}}$ is, however, very wide when $p_{\mathrm{d}}$ is small. Indeed, days without precipitation occur not only during clear weather conditions but also under overcast conditions. Therefore it is difficult to derive $\tau_{\mathrm{d}}$ from $p_{\mathrm{d}}$.

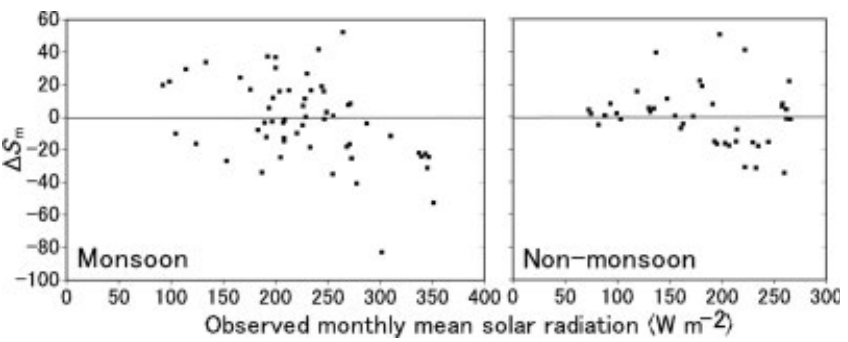

Fig. 6. Estimated minus observed monthly mean solar radiation $\Delta S_{\mathrm{m}}$ as a function of observed monthly mean solar radiation.

We also calculated the monthly atmospheric transmissivity of solar radiation $\tau_{\mathrm{m}}$, which is defined as the ratio of the monthly mean observed $S$ to the monthly mean of $T S_{0}$. Figure 4 shows the relation between $\tau_{\mathrm{m}}$ and monthly mean precipitation rate, $p_{\mathrm{m}}\left(\mathrm{mm} \mathrm{d}^{-1}\right)$, which is monthly precipitation divided by the number of days in the month. There is a favorable correlation between $\tau_{\mathrm{m}}$ and $p_{\mathrm{m}}$, and the approximation of the relation between them is:

$$
\begin{array}{ll}
\tau_{\mathrm{m}}=\left(0.49 \times 0.88^{p_{\mathrm{m}}}\right)+0.20 & \text { (monsoon) } \\
\tau_{\mathrm{m}}=-0.044 p_{\mathrm{m}}+0.74 & \text { (non-monsoon) }
\end{array}
$$

Equation (2) is obtained by weighted least squares. Weight is given as the reciprocal of the number of monthly data at the observation sites (e.g. weight at July 1 st glacier is $1 / 17$ in the monsoon season and 1/21 in the non-monsoon season; see Table 1). The minimum value of $\tau_{\mathrm{m}}$ was set as 0.2 when estimating $\tau_{\mathrm{m}}$ by Equation (2), because of the convergence of $\tau_{\mathrm{d}}$ toward about 0.2 with the increase of $p_{\mathrm{d}}$.

The $\tau_{\mathrm{m}}$ in the non-monsoon season tends to be larger than that in the monsoon season when $p_{\mathrm{m}}$ is the same, presumably due to the change of atmospheric conditions, such as the concentration of water vapor and other gases and aerosol, main cloud types and the intensity and frequency of precipitation.

We estimate monthly mean solar radiation, $S_{\mathrm{m}, \mathrm{e}}$ by means of Equation (2) and calculated $T S_{0}$. The $S_{\mathrm{m}, \mathrm{e}}$ and the observed monthly mean solar radiation, $S_{\mathrm{m}, \mathrm{o}}$, are shown in Figure 5. Correlation coefficients of all $S_{\mathrm{m}, \mathrm{e}}$ and $S_{\mathrm{m}, \mathrm{o}}$ are 0.92 in the monsoon season and 0.96 in the non-monsoon season. The relation between $S_{\mathrm{m}, \mathrm{e}}-S_{\mathrm{m}, \mathrm{o}}\left(\Delta S_{\mathrm{m}}\right)$ and $S_{\mathrm{m}, \mathrm{o}}$ is shown in Figure 6. The average plus and minus standard deviation $(\mathrm{AV} \pm \mathrm{SD})$, maximum (Max) and minimum (Min) values of $\Delta S_{\mathrm{m}}$ at every measurement site are shown in Figure 7. Almost all absolute values of $\Delta S_{\mathrm{m}}\left(\left|\Delta S_{\mathrm{m}}\right|\right)$ are $<40 \mathrm{~W} \mathrm{~m}^{-2}$. However, the ranges of $\Delta S_{\mathrm{m}}$ at D66 and MS3608 are large: $26-52 \mathrm{~W} \mathrm{~m}^{-2}$ at D66, and -53 to $-83 \mathrm{~W} \mathrm{~m}^{-2}$ at MS3608. The spatial variation of complex environmental conditions can cause spatial variation in the relation between precipitation and the effect of clouds on transmissivity of solar radiation; and indeed, $\Delta S_{\mathrm{m}}$ at D66 and MS3608 is excessively large. Therefore, the error of the estimated monthly mean solar radiation by Equation (2) can be significantly large at some places in the Himalaya and the Tibetan Plateau.

\section{Impact of errors in precipitation measurement}

Systematic errors in the measurement of precipitation are caused by wind-induced bias, wetting loss, evaporation loss, and variances in gauge design (Goodison and others, 1998). Even though wetting and evaporation loss can be ignored, the effects of the other two may be significant, particularly 


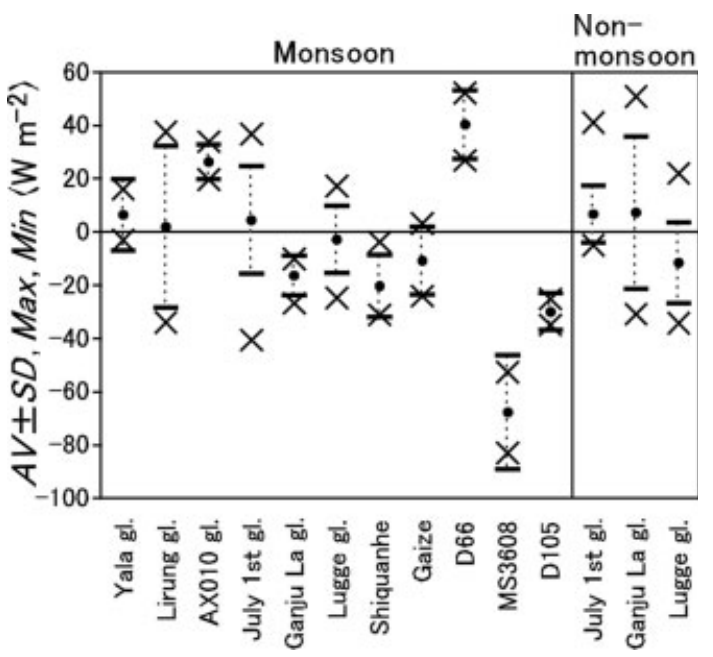

Fig. 7. Average plus and minus standard deviation $(\mathrm{AV} \pm \mathrm{SD})$, and the maximum (Max) and minimum (Min) of $\Delta S_{\mathrm{m}}$ at every measurement site. Cross denotes maximum and minimum values, circle denotes average value, and bar indicates average plus and minus standard deviation.

when solid precipitation occurs. Precipitation can only be corrected to the values of DFIR or bush gauge at D105. Therefore, precipitation at all other sites was tentatively corrected by means of the following formulas by Kondo and Xu (1997):

$$
\begin{gathered}
p_{\mathrm{d}, \mathrm{c}}=\frac{p_{\mathrm{d}, \mathrm{o}}}{C} \\
C=1 \quad\left(\text { when } t_{\mathrm{a}}>11.01-1.5 e:[\text { rain }]\right) \\
C=0.5 \exp (-0.26 s U)+0.5 \exp (-0.16 s U), \\
\quad\left(\text { when } t_{\mathrm{a}} \leq 11.01-1.5 e:[\text { snow }]\right) \\
s=1-\frac{1}{1+\exp \left(11.01-1.5 e-t_{\mathrm{a}}\right)},
\end{gathered}
$$

where $p_{\mathrm{d}, \mathrm{c}}$ and $p_{\mathrm{d}, \mathrm{o}}$ are the corrected and measured daily precipitation $(\mathrm{mm})$, respectively, $t_{\mathrm{a}}$ is daily mean air temperature $\left({ }^{\circ} \mathrm{C}\right)$, e is daily mean vapor pressure $(\mathrm{hPa})$, and $U$ is daily mean wind speed at the height of the gauge orifice $\left(\mathrm{m} \mathrm{s}^{-1}\right)$. According to Goodison and others (1998), $U$ is estimated as:

$$
U=\frac{\ln \left(\frac{h}{z_{0}}\right)}{\ln \left(\frac{H}{z_{0}}\right)} U_{\mathrm{o}}
$$

where $U_{o}$ is the measured daily mean wind speed $\left(\mathrm{m} \mathrm{s}^{-1}\right), h$ and $H$ are the height of the gauge orifice and wind-speed sensor $(\mathrm{m})$, respectively, and $z_{0}$ is roughness length: $0.01 \mathrm{~m}$ for winter and $0.03 \mathrm{~m}$ for summer (Goodison and others, 1998). We used a roughness length of $0.01 \mathrm{~m}$ for the nonmonsoon season and $0.03 \mathrm{~m}$ for the monsoon season. The $e$ is estimated as:

$$
e=6.1078 \times 10^{7.5 t_{\mathrm{a}} /\left(237.3+t_{\mathrm{a}}\right)} \frac{\mathrm{RH}}{100}
$$

where $\mathrm{RH}$ is the daily mean relative humidity (\%). Measurement points of $t_{\mathrm{a}}, \mathrm{RH}$ and $U_{\mathrm{o}}$ are the same as those of solar radiation. When $C$ cannot be calculated due to the lack of data on $t_{\mathrm{a}}, \mathrm{RH}$ and $U_{\mathrm{o}}, C$ is assumed to be 1 during the monsoon season and 0.7 during the non-monsoon season.

Though the error in measuring precipitation by an unheated tipping gauge can cause a critical error, particularly when considerable precipitation occurs under low-temperature conditions, we assumed that this error in monthly precipitation can be ignored, since precipitation is low in the Himalaya and the Tibetan Plateau during the non-monsoon season, and little snow occurs at the precipitation measurement sites during the monsoon season.

As a result of correction by Equations (3-7), precipitation amounts changed at AX010, Ganju La, July 1st and Lugge glaciers and D66. Average and maximum values of the ratios of the corrected precipitation to the measured precipitation are 1.1 and 1.4 in the monsoon season, and 1.5 and 2.2 in the non-monsoon season, respectively. The correction changed Equation (2) to:

$$
\begin{array}{ll}
\tau_{\mathrm{m}}=\left(0.49 \times 0.88^{p_{\mathrm{m}, \mathrm{c}}}\right)+0.20 & \text { (monsoon) } \\
\tau_{\mathrm{m}}=-0.029 p_{\mathrm{m}, \mathrm{c}}+0.74 & \text { (non-monsoon) }
\end{array}
$$

where $p_{\mathrm{m}, \mathrm{c}}$ is the corrected monthly mean precipitation ratio $\left(\mathrm{mm} \mathrm{d}^{-1}\right)$. Though the empirical equation of $\tau_{\mathrm{m}}$ for the nonmonsoon season changes due to the precipitation increase after correction, the equation for the monsoon season is the same as that before the precipitation correction. This is due to the small correction during the monsoon season, with relatively warm (i.e. little snow) and weak wind conditions during this season. The relation between $S_{\mathrm{m}, \mathrm{e}}$ and $S_{\mathrm{m}, \mathrm{o}}$, and that between $\Delta S_{\mathrm{m}}$ and $S_{\mathrm{m}, \mathrm{o}}$ after precipitation correction are almost the same as those without the correction. Correlation coefficients between $S_{\mathrm{m}, \mathrm{e}}$ and $S_{\mathrm{m}, \mathrm{o}}$ after the correction are 0.91 in the monsoon season and 0.96 in the non-monsoon season. The $\mathrm{AV} \pm \mathrm{SD}$, Max and Min of $v$ at every measurement site after the correction are also almost the same as those without the correction. Though precipitation correction may be inappropriate, its effect on the empirical equation of $\tau_{\mathrm{m}}$ seems to be small for the monsoon season, since the corrected precipitation changes little during the monsoon season. However, the relation between $\tau_{\mathrm{m}}$ and $p_{\mathrm{m}}$ should be examined again using the correct precipitation amount for the non-monsoon season.

Even though a proper empirical equation for estimating $\tau_{\mathrm{m}}$ can be obtained, it would be difficult to obtain accurate past precipitation data in mountain regions. Measured precipitation tends to be less than the true value (i.e. $\tau_{\mathrm{m}}$ tends to be overestimated), because measurement errors are caused by the loss of precipitation by wind, evaporation, etc. We estimated the potential overestimation of $\tau_{\mathrm{m}}$ and $S_{\mathrm{m}, \mathrm{e}}$ when the corrected precipitation was less than the actual precipitation. The magnitude of the overestimation of $\tau_{\mathrm{m}}$ $\left(\Delta \tau_{\mathrm{m}}\right)$ is estimated from Equation (2) or (8) as:

$$
\begin{aligned}
\Delta \tau_{\mathrm{m}}= & 0.49\left(0.88^{p_{\mathrm{m}, \mathrm{c}}}-0.88^{p_{\mathrm{m}, \mathrm{t}}} \quad\right. \text { (monsoon) } \\
\Delta \tau_{\mathrm{m}}=- & 0.044\left(p_{\mathrm{m}, \mathrm{c}}-p_{\mathrm{m}, \mathrm{t}}\right) \\
& \quad(\text { from Equation }(2), \text { non-monsoon) }
\end{aligned}
$$

or

$$
\begin{aligned}
\Delta \tau_{\mathrm{m}}=- & 0.029\left(p_{\mathrm{m}, \mathrm{c}}-p_{\mathrm{m}, \mathrm{t}}\right) \\
& (\text { from Equation (8), non-monsoon) }
\end{aligned}
$$

where $p_{\mathrm{m}, \mathrm{t}}$ is the actual monthly mean precipitation rate $\left(\mathrm{mm} \mathrm{d}^{-1}\right)$. When the ratio of $p_{\mathrm{m}, \mathrm{t}}$ to $p_{\mathrm{m}, \mathrm{c}}$ is 1.5 or 2.5 , and when the minimum value of $\tau_{\mathrm{m}}$ is assumed to be 0.2 , the maximum value of $\Delta \tau_{\mathrm{m}}$ is 0.07 or 0.16 for the monsoon season and 0.18 or 0.32 for the non-monsoon season. The monthly mean $S_{0}$ can be about $480 \mathrm{Wm}^{-2}$ during the monsoon season and about $430 \mathrm{~W} \mathrm{~m}^{-2}$ during the nonmonsoon season in the Himalaya and the Tibetan Plateau. 
Thus, the magnitude of $S_{\mathrm{m} \text {, e }}$ overestimation can be 35 or $77 \mathrm{~W} \mathrm{~m}^{-2}$ during the monsoon season and 77 or $138 \mathrm{~W} \mathrm{~m}^{-2}$ during the non-monsoon season. The $\Delta \tau_{\mathrm{m}}$ during the monsoon season becomes maximum when $P_{\mathrm{m}, \mathrm{c}}=6.3 \mathrm{~mm} \mathrm{~d}^{-1}$ $\left(P_{\mathrm{m}, \mathrm{t}} / P_{\mathrm{m}, \mathrm{c}}=1.5\right)$ or $4.8 \mathrm{~mm} \mathrm{~d}^{-1}\left(p_{\mathrm{m}, \mathrm{t}} / p_{\mathrm{m}, \mathrm{c}}=2.5\right)$. Hence, the input precipitation data need to be highly accurate, particularly when $p_{\mathrm{m}, \mathrm{c}}$ is about $5 \mathrm{~mm} \mathrm{~d}^{-1}$. Since there is little precipitation (i.e. $p_{\mathrm{m}, \mathrm{t}}$ and $p_{\mathrm{m}, \mathrm{c}}$ are small) in the Himalaya and the Tibetan Plateau during the non-monsoon season, $\Delta \tau_{\mathrm{m}}$ is generally small during this season. However, it should be noted that the magnitude of $S_{\mathrm{m}, \mathrm{e}}$ overestimation during this season can be excessively large.

\section{CONCLUSIONS}

We examined the relation between the atmospheric transmissivity of solar radiation and precipitation measured in the Himalaya and the Tibetan Plateau. The monthly mean solar radiation was derived from monthly precipitation, latitude, skyline at the measurement site and time.

Although our approach is not suitable for short-term simulations or for high-spatial-resolution studies due to the poor accuracy of the estimated solar radiation, this approach may be useful for computing solar radiation when it cannot be obtained by other methods. For example, after quality control of re-analysis or GCM precipitation data, our method may be helpful to estimate the spatial variations of this solar radiation index over large areas. Since precipitation and temperature are obtainable from ice cores and tree rings in the Himalaya and the Tibetan Plateau (e.g. Yao and Thompson, 1992; Thompson and others, 2003; Zhang and others, 2003), this approach will be useful to evaluate the paleo-condition of glacier mass balance from limited proxies.

\section{ACKNOWLEDGEMENTS}

This study is based on data obtained by the Japan-Nepal joint research Glaciological Expedition in Nepal (GEN); the China-Japan joint project Cryosphere Research in Qingzang Plateau (CREQ); the Japan-Bhutan Joint Research on the assessment of Glacier Lake Outburst Flood in Bhutan; the Oasis project (Historical evolution of adaptability in an oasis region to water resource changes) promoted by the National Institute for Humanity and Nature, Japan; and GAME-Tibet, which is a regional experiment of the GAME (GEWEX (Global Energy and Water Cycle Experiment) Asia Monsoon Experiment). We express our sincere thanks to all members participating in these projects.

\section{REFERENCES}

Ageta, Y. and S. Kohshima. 2004. Report of Japan-Bhutan joint research 2003 on the assessment of Glacier Lake Outburst Flood (GLOF) in Bhutan. Nagoya, Nagoya University. Graduate School of Environmental Studies; Tokyo, Tokyo Institute of Technology. Graduate School of Bioscience and Biotechnology; Thimphu, Geological Survey of Bhutan.

Ageta, Y., T. Ohata, Y. Tanaka, K. Ikegami and K. Higuchi. 1980. Mass balance of glacier AX010 in Shorong Himal, east Nepal during the summer monsoon season. Seppyo, J. Jpn. Soc. Snow Ice, 41, Special Issue, 34-41.

Bamber, J.L. and A.J. Payne. 2004. Mass balance of the cryosphere: observations and modelling of contemporary and future changes. Cambridge, etc., Cambridge University Press.
Bintanja, R. and M.R. van den Broeke. 1996. The influence of clouds on the radiation budget of ice and snow surfaces in Antarctica and Greenland in summer. Int. J. Climatol., 16(11), 1281-1296.

Braithwaite, R.J. and Y. Zhang. 2000. Sensitivity of mass balance of five Swiss glaciers to temperature changes assessed by tuning a degree-day model. J. Glaciol., 46(152), 7-14.

Casal, T.G.D., J.E. Kutzbach and L.G. Thompson. 2004. Present and past ice-sheet mass balance simulations for Greenland and the Tibetan Plateau. Climate Dyn., 23(3-4), 407-425.

Chalise, S.R., M.L. Shrestha, K.B. Thapa, B.R. Shrestha and B.B. Bajracharya. 1996. Climatic and hydrological atlas of Nepal. Kathmandu, International Centre for Integrated Mountain Development.

Chen, T.-C., W.-R. Huang and E.S. Takle. 2004. Annual variation of midlatitude precipitation. J. Climate, 17(21), 4291-4298.

Dai, J. 1990. Climate of Qinghai-Tibetan Plateau.. In Dai, J., ed. Climate on the Tibetan Plateau. Beijing, Meteorological Press, 51-196. [In Chinese.]

Ding, L. and X. Kang. 1985. Climatic conditions for the development of glaciers and their effect on the characteristics of glaciers in Qilian Mountains. Mem. Lanzhou Inst. Glaciol. Geocryol., 5, 9-15. [In Chinese.]

Dobson, F.W. and S.D. Smith. 1989. A comparison of incoming solar radiation at marine and continental stations. Q.J.R. Meteorol. Soc., 115(486), 353-364.

Duan, K. and T. Yao. 2003. Monsoon variability in the Himalayas under the condition of global warming. J. Meteorol. Soc. Jpn, $\mathbf{8 1}(2), 251-257$.

Dyurgerov, M.B. and M.F. Meier. 1997. Year-to-year fluctuations of global mass balance of small glaciers and their contribution to sea-level changes. Arct. Alp. Res., 29(4), 392-402.

Feng, S. and Q. Hu. 2005. Regulation of Tibetan Plateau heating on variation of Indian summer monsoon in the last two millennia. Geophys. Res. Lett., 32(2), L02702. (10.1029/2004GL021246.)

Fujita, K. and Y. Ageta. 2000. Effect of summer accumulation on glacier mass balance on the Tibetan Plateau revealed by massbalance model. J. Glaciol., 46(153), 244-252.

Fujita, K., A. Sakai and T.B. Chhetri. 1997. Meteorological observation in Langtang valley, Nepal Himalaya. Bull. Glacier. Res., 15, 71-78.

Glover, R.W. 1999. Influence of spatial resolution and treatment of orography on GCM estimates of the surface mass balance of the Greenland Ice Sheet. J. Climate, 12(2), 551-563.

Goodison, B.E., P.Y.T. Louie and D. Yang. 1998. WMO solid precipitation measurement intercomparison: results and challenges for the future. In Proceedings of WMO Technical Conference on Meteorological and Environmental Instruments and Methods of Observation (TECO-98). Geneva, World Meteorological Organization, 19-22.

Greuell, W., W.H. Knap and P.C. Smeets. 1997. Elevational changes in meteorological variables along a mid-latitude glacier during summer. J. Geophys. Res., 102(D22), 25,941-25,954.

Hock, R. 1999. A distributed temperature-index ice- and snowmelt model including potential direct solar radiation. J. Glaciol., 45(149), 101-111.

Hock, R. 2003. Temperature index melt modelling in mountain areas. J. Hydrol., 282(1-4), 104-115.

Houghton, J.T. and 7 others. 2001. Climate change 2001: the scientific basis. Contribution of Working Group I to the Third Assessment Report of the Intergovernmental Panel on Climate Change. Cambridge, etc., Cambridge University Press.

Kalnay, E. and 21 others. 1996. The NCEP/NCAR 40-year reanalysis project. Bull. Am. Meteorol. Soc., 77(3), 437-471.

Kayastha, R.B., T. Ohata and Y. Ageta. 1999. Application of a massbalance model to a Himalayan glacier. J. Glaciol., 45(151), 559-567.

Kayastha, R.B., Y. Ageta and M. Nakawo. 2000. Positive degree-day factors for ablation on glaciers in the Nepalese Himalayas: case study on Glacier AXOIO in Shorong Himal, Nepal. Bull. Glaciol. Res., 17, 1-10. 
Kayastha, R.B., Y. Ageta, M. Nakawo, K. Fujita, A. Sakai and Y. Matsuda. 2003. Positive degree-day factors for ice ablation on four glaciers in the Nepalese Himalayas and Qinghai-Tibetan Plateau. Bull. Glaciol. Res., 20, 7-14.

Kondo, J., and J. Xu. 1997. Seasonal variations in the heat and water balances for nonvegetated surfaces. J. Appl. Meteorol., 36(12), 1676-1695.

Liu, X. and B. Chen. 2000. Climatic warming in the Tibetan Plateau during recent decades. Int. J. Climatol., 20(14), 1729-1742.

Liu, C., E. Kang, S. Liu, J. Chen and Z. Liu. 1999. Study on the glacier variation and its response in the arid region of Northwest China. Sci. China D, 42(suppl.), 64-71.

Martinec, J. 1989. Hour-to-hour snowmelt rates and lysimeter outflow during an entire ablation period. IAHS Publ. 183 (Symposium at Baltimore 1989 - Snow Cover and Glacier Variations), 19-28.

Matsuda, Y., A. Sakai, K. Fujita, M. Nakawo, K. Duan, J. Pu and T. Yao. 2004. Glaciological observations on July 1st glacier in Qilian Mountains of west China during summer 2002. Bull. Glaciol. Res., 21, 31-36.

Oerlemans, J. 1993. A model for the surface balance of ice masses: part I. Alpine glaciers. Z. Gletscherkd. Glazialgeol., 27-28, 1991-92, 63-83.

Oerlemans, J. 2001. Glaciers and climate change. Lisse, etc., A.A. Balkema.

Ohata, T. and K. Higuchi. 1980. Heat balance study on glacier AX010 in Shorong Himal, east Nepal. Seppyo, J. Jpn. Soc. Snow Ice, 41, Special Issue, 42-47.

Ohta, T. and Y. Ageta. 1996. Data report of cryosphere research on Qingzang Plateau, 1991-1993. Nagoya, Nagoya University. Institute for Hydrospheric-Atmospheric Science. (IAHS Research Report 2.)

Reichert, B.K., L. Bengtsson and J. Oerlemans. 2001. Midlatitude forcing mechanisms for glacier mass balance investigated using general circulation models. J. Climate, 14(17), 3767-3784.

Seko, K., J. Pu, K. Fujita, Y. Ageta, T. Ohata and T. Yao. 1994. Glaciological observations in the Tanggula Mts., Tibetan Plateau. Bull. Glacier Res., 12, 57-67.
Shiobara, M. and S. Asano. 1992. The dome emission effect on the performance of pyrgeometers with silicon domes. Pap. Meteorol. Geophys., 43(1), 17-31. [In Japanese with English abstract.]

Sicart, J.E., P. Wagnon and P. Ribstein. 2005. Atmospheric controls of the heat balance of Zongo Glacier $\left(16^{\circ} \mathrm{S}\right.$, Bolivia). J. Geophys. Res., 110(D12), D12106. (10.1029/2004JD005732.)

Simmons, A.J. and J.K. Gibson. 2000. The ERA-40 project plan. Reading, European Centre for Medium-Range Weather Forecasts. (ERA-40 Project Report Series 1.)

Singh, J. and R.R. Yadav. 2005. Spring precipitation variations over the western Himalaya, India, since A.D. 1731 as deduced from tree rings. J. Geophys. Res., 110(D1), D01110. (10.1029/ 2004JD004855.)

Thompson, L.G., E. Mosley-Thompson, M.E. Davis, P.N. Lin, K. Henderson and T.A. Mashiotta. 2003. Tropical glacier and ice core evidence of climate change on annual to millennial time scales. Climatic Change, 59(1-2), 137-155.

Ueno, K. and T. Ohata. 1996. The importance of the correction of precipitation measurements on the Tibetan Plateau. J. Meteorol. Soc. Jpn, 74(2), 211-220.

Walter, M.T., E.S. Brooks, D.K. McCool, L.G. King, M. Molnau and J. Boll. 2005. Process-based snowmelt modeling: does it require more input data than temperature-index modeling? J. Hydrol., 300(1-4), 65-75.

Wang, S., D. Gong and J. Zhu. 2001. Twentieth-century climatic warming in China in the context of the Holocene. Holocene, 11(3), 313-321.

Wild, M. and A. Ohmura. 2000. Change in mass balance of polar ice sheets and sea level from high-resolution GCM simulations of greenhouse warming. Ann. Glaciol., 30, 197-203.

$\mathrm{Xu}$, J. and S. Haginoya. 2001. An estimation of heat and water balances in the Tibetan Plateau. J. Meteorol. Soc. Jpn, 79(1B), 485-504.

Yao, T. and L.G. Thompson. 1992. Trends and features of climatic changes in the past 5000 years recorded by the Dunde ice core. Ann. Glaciol., 16, 21-24.

Zhang, Q., G. Cheng, T. Yao, X. Kang and J. Huang. 2003. A 2,326year tree-ring record of climate variability on the northeastern Qinghai-Tibetan Plateau. Geophys. Res. Lett., 30(14), 1739. (10.1029/2003GL017425.) 